\title{
Studies on Burying Ability in Sand and Selection to the Grain Size for Hatchery-reared Marbled Sole and Japanese Flounder
}

\author{
Minoru Tanda*1 \\ (Received November 28, 1989)
}

\begin{abstract}
The burying ability and grain size selection of hatchery-reared marbled sole and Japanese flounder juveniles were studied using sand of various grain sizes.

Sand obtained from fishing areas were categorized into six grain-sizes: $\sim 0.125 \mathrm{~mm}$, $0.125 \sim 0.25 \mathrm{~mm}, 0.25 \sim 0.5 \mathrm{~mm}, 0.50 \sim 1.0 \mathrm{~mm}, 1.0 \sim 2.0 \mathrm{~mm}$ and $2.0 \sim 2.83 \mathrm{~mm}$. The buried area was visually measured. Marbled sole juveniles from all three size groups (The means of the total lengths were $35.0,58.7$ and $80.6 \mathrm{~mm}$.) were able to bury themselves in sand consisting of grains smaller than $1 \mathrm{~mm}$ in diameter. However, in sand with a diameter larger than $1 \mathrm{~mm}$, only the $80.6 \mathrm{~mm}$ group was able to bury themselves. Thus, the burying ability increased with growth.

Sands of two different grain sizes were laid on both halves of the bottom of the container. Marbled sole $(35.0 \mathrm{~mm}$ TL) and flounder $(55.7 \mathrm{~mm}$ TL) preferred medium grain sizes, $0.125 \sim 0.5 \mathrm{~mm}$ in diameter. A positive correlation between the preference index and the buried area was found in both species. It is suggested that the juveniles preferred the type of sand in which they can bury themselves most easily.
\end{abstract}

The marbled sole Limanda yokohamae and the Japanese flounder Paralichthys olivaceus are distributed in waters around Japan and both species are commercially important. The juveniles are mass-produced for enhancement of stock and are released into the sea. These juvenile fish must be released at an optimum time and place to give them the best chance of survival and recruitment to the adult stock. However, mainly due to lack of fundamental information on behavior of the juveniles, this has not yet been fully realized.

Among the factors concerning successful release, the condition of the seabed is particularly important for flatfishes. Although we can find various papers on the ecology of these two species, ${ }^{1-3)}, 2-4$ substratum preference remains poorly understood. The main purpose of this study is to examine the burying ability in sand and preference for grain size in marbled sole and Japanese flounder juveniles.

\section{Materials and Methods}

\section{Materials}

1. Fish: We obtained marbled sole juveniles, averaging $21 \mathrm{~mm}$ in total length, from Hyogo Prefectural Mariculture Center. The rearing period started on March 3 and ended on Septem -ber 27,1988 . They were reared in a 1-ton polycarbonate tank $(\phi 138 \mathrm{~cm} \times 82 \mathrm{~cm}$ depth $)$ and fed on Artemia sp. and pellets. Sand was not used on the bottom during the preliminary rearing. The flounder juveniles were hatched and reared in Kobe Municipal Mariculture Center. They were

*1 Hyogo Prefectural Fisheries Experimental Station, Akashi, Hyogo 673, Japan（反田 宾：兵庫娊立 水産試駼暢).

*2 Kagawa, Okayama, Fukuoka, Ooita and Yamaguchi Prefectural Fisheries Experimental Station: Summarized report on the development of fish releasing techniques-flatfishes (S. 46-49), 1975, pp. $1-51$.

*3 Ooita, Yamaguchi Prefectural Fisheries Experimental Station and Yamaguchi Prefectural Seafarming Center: Summarized report on the development of fish releasing techniques (marbled sole), 1985 , pp. 1-25.

* Aomori, Yamagata, Toyama, Shimane, Kumamoto Prefectural Fisheries Experimental Statiou and Aomori, Iwate, Yamagata, Niigata, Toyama, Tottori, Shimane, Okayama, Kumamoto Prefectural Sea-farming Center: Summarized report on the project for development of releasing techniques (Japanese flounder group: S. 55-59), 1985, pp. 1-55. 
Table 1. Grain size divisions of sand

\begin{tabular}{c} 
Grain size $(\mathrm{mm})$ \\
$\sim 0.125$ \\
$0.125 \sim 0.250$ \\
$0.250 \sim 0.500$ \\
$0.500 \sim 1.00$ \\
$1.00 \sim 2.00$ \\
$2.00 \sim 2.83$ \\
\hline
\end{tabular}

transferred to the laboratory on July 6,1988 and were reared until September 27, 1988. The rearing conditions were the same as for the marbled sole.

2. Sand: Sand, collected from the fishing area, was passed through a sieve to obtain 6 different sizes (Table 1) using sieves in conformity with JS (Japanese Industrial Standards). Sixty three percent of the total weight of the $\sim 0.125 \mathrm{~mm}$ category consisted of granules smaller than 0.063 $\mathrm{mm}$. The sand was washed in fresh water and dried at $130^{\circ} \mathrm{C}$ twice. The size categories of $\sim 0.125 \mathrm{~mm}$ and $0.125 \sim 0.25 \mathrm{~mm}$ appeared grayish and the others brownish in color but they were all free of odor. In a preliminary experiment on marbled sole two different colors of sand (whitish and brownish) with $0.25 \sim 0.5 \mathrm{~mm}$ grain size were used. There was no significant difference in the results obtain- ed when using sand of two colors (Table 2). There- fore, it was assumed that there was no significant influence on the preference index when using sand of different colors.

\section{Methods}

1. Degree of concealment: This experiment was performed only with the marbled sole, since the same experiment had been performed with the fiounder. ${ }^{4}$ The marbled soles were divided into three size classes according to total length: $35.0 \mathrm{~mm}$ (S.D. $=4.3 \mathrm{~mm}, \mathrm{n}=73$ ), $58.7 \mathrm{~mm}$ (S.D. $=4.2 \mathrm{~mm}$, $\mathrm{n}=24)$ and $80.6 \mathrm{~mm}($ S.D. $=5.6 \mathrm{~mm}, \mathrm{n}=21)$. Sand was laid on the bottom of $10 \mathrm{l}$ plastic containers ( $36 \mathrm{~cm}$ long, $23 \mathrm{~cm}$ wide and $13 \mathrm{~cm}$ depth), to a thickness of $1 \sim 2 \mathrm{~cm}$. Three to ten juveniles were transferred from the 1-ton stock tank to each container. The degree of concealment was measured visually one hour after transfer. This was defined as a per centage of buried area to the whole area of the ocular side of a juvenile and was measured to the nearest $10 \%$. The experiment was repeated 5 8 times with each grain size for each size group. The experimental tanks were placed in the laboratory under 150 1500 lx at the water surface. Water temperatures were not controlled and ranged between $11.0 \sim 25.0^{\circ} \mathrm{C}$.

2. Preference for grain size: The six grain-size divisions which were used in the size preference experiments were the same as for the burying experiment. Five $10 /$ plastic containers (same size as in the burying experiments) were placed in the laboratory. Sand of $0.25 \sim 0.5 \mathrm{~mm}$ grain size was laid on half the area of the bottom of each container in a $1 \sim 2 \mathrm{~cm}$ layer. The preference for this grain size was compared with that for other grain sizes. It was found, after the preliminary observation, that medium size sand of $0.25 \sim 0.5 \mathrm{~mm}$ was the most attractive. The other halves of the containers were covered with sand other than the medium size. Six marbled sole juveniles (four flounder) were transferred to each container, three fish on each grain size. The number of fish located on each substratum were counted 2 hours after the transfer of juveniles. The experiment was repeated 10 21 times for each combination. The light intensity was $200 \sim 1500 \mathrm{~lx}$ at the water surface, and to reduce the light-intensity effects the orientation of the container was alternately turned $180^{\circ}$ for every observation. The $35.0 \mathrm{~mm}$ size group was used for this experiment. Water temperatures were not controlled and fluctuated between $11.1 \sim 11.9^{\circ} \mathrm{C}$. A similar experiment was also performed for flounder juveniles averaging $55.7 \mathrm{~mm}($ S.D. $=4.5 \mathrm{~mm}, \mathrm{n}=34)$ in total ength.

In another experiment for the preference of grain size, the right and left halves of the container bottoms ( $60 \mathrm{~cm}$ long, $40 \mathrm{~cm}$ wide, $20 \mathrm{~cm}$ depth) were covered with two different grain sizes of sand, $0.25 \sim 0.5 \mathrm{~mm}$ and $1 \sim 2 \mathrm{~mm}$. Two groups consisting of six individuals of marbled sole and flounder were used for the first experiment, and ten juveniles for the second experiment. Half of the individuals of each species were carefully transferred to one side and the others to the opposite side of the container. The number of juveniles located on each side was counted 2 or 3 hours after transfer. The first and second experiments consisted of 21 and 16 observations, respectively. The size of juveniles used in the experiments were $70.7 \mathrm{~mm}$ TL (S.D. $=3.6 \mathrm{~mm}, \mathrm{n}=25$ ) with marbled sole and $74.3 \mathrm{~mm}$ TL (S.D. $=5.3 \mathrm{~mm}, \mathrm{n}=22$ ) with fluounder. Juveniles of both species treated here did not show any apparent aggressive or exclusive behavior. 


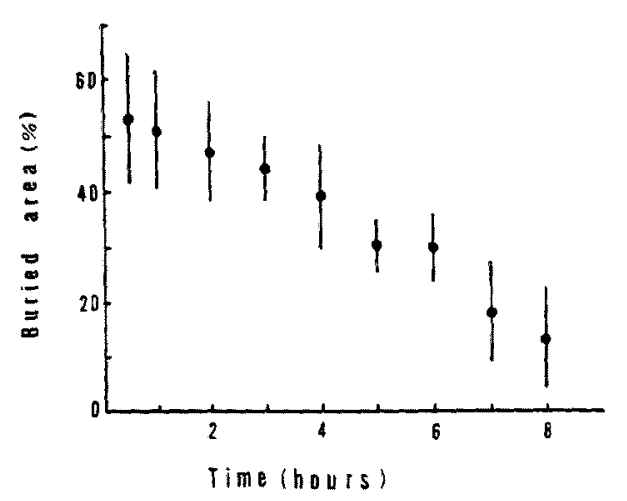

Fig. 1. Change in time of buried area of marbled sole juveniles averaging $35.0 \mathrm{~mm}$ TL. $0.25 \sim$ $0.5 \mathrm{~mm}$ grain size sand was used. The experiment was repeated three times. Vertical bars represent standard deviation.

\section{Results}

\section{Degree of Concealment}

The time-related changes in buried area of $35 \mathrm{~mm}$-size marbled sole juveniles, examined under $0.25 \sim 0.5 \mathrm{~mm}$ grain size, are shown in Fig. 1. A majority of the juveniles buried their body into the sand immediately after transfer to the container. The average buried area was $53 \% 30 \mathrm{~min}$. after transfer, but decreased gradually with time: $47 \%$ ( $2 \mathrm{hrs}), 39 \%(4 \mathrm{hrs})$ and $14 \%(8 \mathrm{hrs})$. This change with time differed from that of flounder juveniles, ${ }^{4}$ in which the degree of concealment reached a maximum three or four hours after transfer with gradual decreases later. From this result, we decided to measure the degree one hour after transfer in the subsequent experiments.

The relation between the buried area and grain size is shown in Fig. 2. The buried area for grain

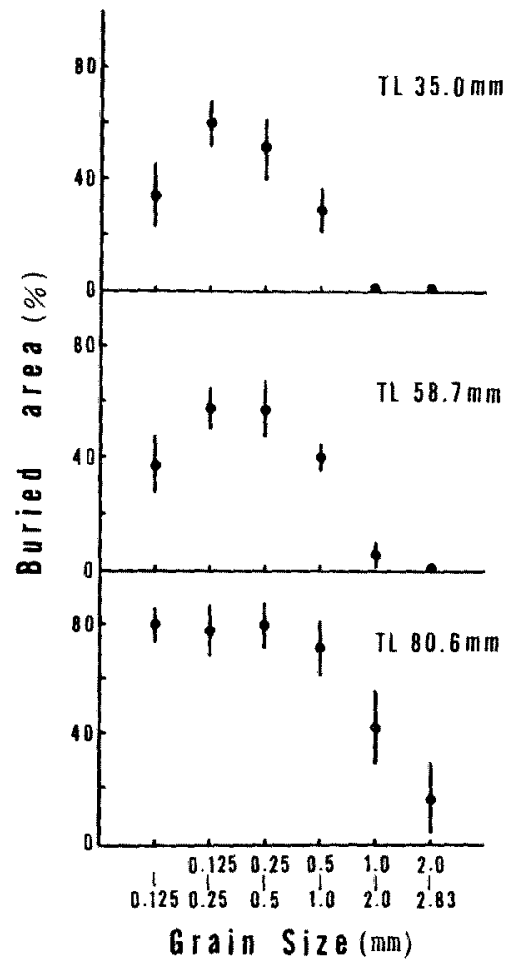

Fig. 2. Relationship between grain size and buried area in three size-group marbled sole juveniles: $35.0 \mathrm{~mm}, 58.7 \mathrm{~mm}$ and $80.6 \mathrm{~mm}$ TL. Vertical bars represent standard deviation.

sizes of $0.125 \sim 0.25 \mathrm{~mm}$ and $0.25 \sim 0.5 \mathrm{~mm}$ indicated the maximum value among all divisions in every size-group. Although the buried area for $\sim 0.125 \mathrm{~mm}$ grain size was low in $35.0 \mathrm{~mm}$ and $58.7 \mathrm{~mm}$ size-groups, the general trend exhibited was a negative relationship between the buried area and grain size in the three size-groups. A positive

Table 2. Preference for grain size of sand in marbled sole juveniles averaging $35.0 \mathrm{~mm} \mathrm{TL}$. Number of juveniles located in the two divisions was examined by $x^{2}$ test. Expected ratio is $50: 50$.

\begin{tabular}{|c|c|c|c|c|}
\hline \multirow{2}{*}{$\begin{array}{l}\text { Combination of } \\
\text { grain sizes (mm) }\end{array}$} & \multirow{2}{*}{$\begin{array}{l}\text { Total number } \\
\text { examined }\end{array}$} & \multicolumn{2}{|c|}{ Number located in } & \multirow{2}{*}{$\begin{array}{l}\text { Statistical } \\
\text { significance (P) }\end{array}$} \\
\hline & & $0.25 \sim 0.5 \mathrm{~mm}$ & Other size & \\
\hline $0.25 \sim 0.5$ vs. & 125 & $80(64) * 1$ & $45(36)$ & 0.01 \\
\hline $0.25 \sim 0.5$ vs, $0.125 \sim 0.250$ & 100 & $51(51)$ & $49(49)$ & ns \\
\hline $0.25 \sim 0.5$ vs. $0.500 \sim 1.00$ & 106 & $66(62)$ & $40(38)$ & 0.05 \\
\hline $0.25 \sim 0.5$ vs. $1.00 \sim 2.00$ & 74 & $67(91)$ & $7(9)$ & 0.01 \\
\hline $0.25 \sim 0.5$ vs. $2.00 \sim 2.83$ & 59 & $51(86)$ & $8(14)$ & 0.01 \\
\hline $\begin{array}{ll}0.25 \sim 0.5 \text { vs. } & 0.25 \sim 0.5^{* 2} \\
\text { (whitish) } & \text { (brownish) }\end{array}$ & 122 & $59(48)$ & $63(52)$ & ns \\
\hline
\end{tabular}

* Figures in parentheses show percentage.

* Result in a preliminary experiment (different sand color). 
Table 3. Preference for grain size of sand in flounder juveniles averaging $55.7 \mathrm{~mm} \mathrm{TL}$. Number of juveniles located in the two divisions was examined by $x^{2}$ test. Expected ratio is $50: 50$.

\begin{tabular}{|c|c|c|c|c|}
\hline \multirow{2}{*}{$\begin{array}{l}\text { Combination of } \\
\text { grain sizes (mm) }\end{array}$} & \multirow{2}{*}{$\begin{array}{l}\text { Total number } \\
\text { examined }\end{array}$} & \multicolumn{2}{|c|}{ Number located in } & \multirow{2}{*}{$\begin{array}{l}\text { Statistical } \\
\text { significance (P) }\end{array}$} \\
\hline & & $0.25 \sim 0.5 \mathrm{~mm}$ & Other size & \\
\hline $0.25 \sim 0.5$ vs. & 79 & $56(71)^{*}$ & $23(29)$ & 0.01 \\
\hline $0.25 \sim 0.5$ vs. $0.125 \sim 0.250$ & 79 & $39(49)$ & $40(51)$ & $\mathrm{ns}$ \\
\hline $0.25 \sim 0.5$ vs. $\quad 0.500 \sim 1.00$ & 82 & $47(57)$ & $35(43)$ & ns \\
\hline $0.25 \sim 0.5$ vs. $1.00 \sim 2.00$ & 81 & $57(70)$ & $24(30)$ & 0.01 \\
\hline $0.25 \sim 0.5$ vs. $2.00 \sim 2.83$ & 82 & $69(84)$ & $13(16)$ & 0.01 \\
\hline
\end{tabular}

* Figures in parentheses show percentage.

Table 4. Preference for grain size of sand when the marbled sole $(70.7 \mathrm{~mm}$ TL) and founder $(74.3 \mathrm{~mm} \mathrm{TL})$ were put together in an experimental container. In case A 6 juveniles of each species were put into the container, and in $B 10$ juveniles each. If the data for both case $A$ and $B$ experiments are combined in a Mantel-Haenszel test, the result is significant $(p=0.021)$.

Case A

\begin{tabular}{lccc}
\hline & Grain size (mm) & Total \\
\cline { 2 - 3 } & $0.25 \sim 0.5$ & $1.0 \sim 2.0$ & number \\
\hline Marbled sole & 88 & 38 & 126 \\
Flounder & 77 & 49 & 126 \\
Total number & 165 & 87 & 252 \\
\hline Case B & & & \\
\hline & Grain size (mm) & Total \\
\hline & $0.25 \sim 0.5$ & $1.0 \sim 2.0$ & number \\
\hline Marbled sole & 117 & 43 & 160 \\
Flounder & 101 & 59 & 160 \\
Total number & 218 & 102 & 320 \\
\hline
\end{tabular}

relationship between the buried area and fish size was recognized. In the largest size group of $80.6 \mathrm{~mm} \mathrm{TL}$, the buried areas of more than $40 \%$ were found in $1 \sim 2 \mathrm{~mm}$ grain size in contrast to nearly $0 \%$ in the other two size-groups. These facts show that the burying ability becomes more developed with growth.

\section{Preference for Grain Size}

1. Marbled sole: The results obtained in this experiment for preference of marbled sole for grain size are summarized in Table 2. Significant differences of $1 \%$ level by $\chi^{2}$ test were recognized in the combinations of the $0.25 \sim 0.5 \mathrm{~mm}$ and $\sim 0.125 \mathrm{~mm}, \quad 1 \sim 2 \mathrm{~mm}, 2 \sim 2.83 \mathrm{~mm}$. The difference was significant at the $5 \%$ level in the 0.25 $\sim 0.5 \mathrm{~mm}$ and $0.5 \sim 1 \mathrm{~mm}$ combination. Mean- while, there was no significant difference in the $0.25 \sim 0.5 \mathrm{~mm}$ and $0.125 \sim 0.25 \mathrm{~mm}$ combination.

2. Japanese founder: The results obtained in this experiment for preference of flounder for grain size are summarized in Table 3. Significant differences from an expected ratio of 50:50 were observed with the combinations of $0.25 \sim 0.5 \mathrm{~mm}$ with $\sim 0.125 \mathrm{~mm}, 1 \sim 2 \mathrm{~mm}, 2 \sim 2.83 \mathrm{~mm}$ ( $\chi^{2}$ test, $\mathrm{p}<0.01)$. No significant differences were found with the combinations of $0.25 \sim 0.5 \mathrm{~mm}$ with $0.125 \sim 0.25 \mathrm{~mm}, 0.5 \sim 1 \mathrm{~mm}$.

3. Marbled sole and flounder: The results for this experiment, which aimed to examine the speciesspecific difference between the two species are shown in Table 4. Experiments with 6 juveniles (case A) and 10 juveniles (case B) of each species both show a slight preference of marbled sole for the finer sand $(0.25 \sim 0.5 \mathrm{~mm}$ in grain size). This difference between the two species was significant (Mantel-Haenszel test, $\mathrm{p}=0.021$ ).

\section{Discussion}

In the present experimental conditions, $35 \mathrm{~mm}$ size and $58.7 \mathrm{~mm}$-size marbled sole juveniles were able to bury themselves in sand of less than $1 \mathrm{~mm}$ in diameter and, except for less than $\sim 0.125 \mathrm{~mm}$ grain size, a negative relationship between the buried area and grain size was found. A similar tendency was observed in Japanese flounder juveniles. ${ }^{4}$ The increase in burying ability with growth was inferred from the experimental result that the degree of concealment was higher in larger-size groups, and that the largest group of $80.6 \mathrm{~mm}$ TL was able to bury themselves even in $1 \sim 2 \mathrm{~mm}$ sand. This trend seems to show an enlargement of habitat of juvenile marbled soles as they grow. From the tendency above, mentioned juveniles should be released at an appro. priate place for their size-related burying abilities.

In the Seto Inland Sea, juvenile and immature 


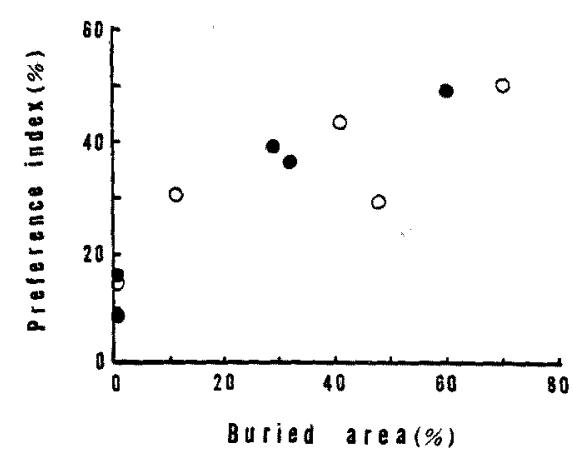

Fig. 3. Relationship between buried area and preference index in marbled sole (solid circle) and flounder juveniles (open circle). These figures were obtained from results cited in Fig. 2, Table 2, Table 3 and the buried area of flounder juveniles obtained in a previous experiment. ${ }^{4}$

marbled soles are more abundant in areas covered with coarse and medium sands than in areas with fine sand and silt in Suo-nada.*1 Meanwhile, juveniles are observed most frequently in fine sand areas during the period from April through June in the coastal areas of Okayama Prefecture.*2 In the northern part of Japan, many of the juveniles inhabit a sandy area, most of which is composed of grains smaller than $0.15 \mathrm{~mm}$, in Mangoku inlet, $*$ whereas the juveniles have been found to be distributed in a silty area of Sendai Bay.*4 There seems to be considerable discrepancies of substratum types for juvenile marbled sole habitats, according to locality. Some of the discrepancies may be caused by the size or growth differences between locations. In connection with the relationship between the grain size and juvenile distribution in flounder, Ishida et al. ${ }^{3)}$ reported that the juveniles are most abundantly distributed in fine sand $(\phi=0.17 \mathrm{~mm})$ and are scarce on both coarse $(\phi=1.0 \mathrm{~mm})$ and very fine $(\phi=0.09 \mathrm{~mm})$ sand areas.

Kosaka $^{(8)}$ demonstrated that young marbled soles settled more easily on sand than on gravel substratum. This trend was observed more clearly in marbled sole than in stone flounder,
Kareius bicoloratus under experimental conditions. The results also support the possibility that substratum grain size may be an important factor in habitat selection. In the present experiments marbled sole and flounder juveniles clearly exhibited preferences related to sand grain size. The relationships between preference index and buried area in both species are shown in Fig. 3. The positive correlations found in both species suggest that those juveniles prefer sand in which they can bury themselves more easily.

Yasunaga and Koshiishi ${ }^{7 /}$ showed that Japanese flounder juveniles are less vulnerable to predation by black sea bream Acanthopagrus schlegeli, when the bottom of the tank was covered with sand. This means that burying behavior is ecologically important in minimizing predation risk. Therefore it was concluded that the substratum was a very important factor for survival of flatfish juveniles in relation to their burying ability.

The tendency of marbled soles to choose sandgrain smaller than those preferred by fiounders was demonstrated in the present experiment. The difference was small but statistically significant. As previously cited, the marbled sole exhibits a stronger preference for sand than gravel substrata as compared with stone flounder, under the same experimental conditions. ${ }^{\theta)}$ In his reviews for the early life history of pleuronectiforms, Minami ${ }^{8)}$ shows species-specific nursery habitats. This habitat segregation may be attributed to the physical conditions of the seabed, such as the grain size of the substratum.

\section{Acknowledgements}

I am very grateful to Dr. M. Tanaka and Mr. J. B. Tanangonan, Department of Fisheries, Kyoto University and Dr. R.S. Batty, Dunstaffnage Marine Laboratory for useful suggestions and critical reading of the manuscript. I also thank Mr. K. Nakamoto, Hyogo Prefectural Fisheries Experimental Station for technical assistance in the rearing experiments.

${ }^{*}$ H. Ito, Y. Masaki and Y. Yamaguchi: Progress report on Marine Ranching Project-Pleuronectiforms (1), 1985, pp. 41-47.

*2 S. Matsumura, H. Hattori, M. Shinohara and S. Terashima: Progress report on the Seto Inland Sea-farming Projectwish releasing tecniques (flatfishes and crabs), 1974, pp. 1-48.

* Miyagi Prefectural Fisheries Experimental Station: Summarized report of the project for development of releasing techniques (marbled sole), 1982, pp. 1-30.

* Miyagi Prefectural Fisheries Experimental Station: Summarized report of the ecological investigations on the sea-farming grounds of the central Pacific coast (S. 47-49), 1975, pp. 1-58. 


\section{References}

1) T. Minami: Nippon Suisan Gakkaishi, 47, 1411-1419 (1981).

2) T. Minami: Nippon Suisan Gakkaishi, 48 , 1581-1588 (1982).

3) M. Tanaka: Fisheries Engineering, 24, 33-44 (1988).

4) M. Tanda: Suisanzoshoku, 36, 21-25 (1988).
5) O. Ishida, K. Tanaka, S. Sato, and Y. Shyoji: Bull. Chiba Pref. Fish. Exp. Stn., 36, 23-31 (1977).

6) M. Kosaka: Nippon Suisan Gakkaishi, 22, 284-288 (1956).

7) Y. Yasunaga and Y. Koshiishi: Bull. Japan Sea Reg. Fish. Res. Lab, 31, 17-31 (1980).

8) T. Minami: Aquabiology, 53, 408-414 (1987). 